\title{
A CRIMINALIZAÇÃO DA POLÍtICA REALIZADA NAS MANIFESTAÇÕES DE 2013, RETRATADA NAS PRODUÇÕES LITERÁRIAS ESTUDANTIS DE UM COLÉGIO ESTADUAL DO SUDOESTE BAIANO
}

Valdimir Pereira Reis*

\section{RESUMO}

O presente trabalho tem o objetivo de analisar como as ideias de criminalização da política defendida nas manifestações de 2013 reverberou nas produções literárias dos estudantes de um colégio estadual no sudoeste baiano. Neste estudo, tomou-se como objeto de pesquisa a influência das manifestações de 2013 nas produções estudantis. Para tanto, foi usado os referenciais de Souza (2016, 2017, 2018) quando afirma que as manifestações de 2013 foi o início do cerco ideológico que resultaram no impedimento da presidenta eleita. O estudo identificou a existência de um elo de influências entre as manifestações e as ideias defendidas pelos estudantes. Identificou-se que os alunos foram vítimas da violência simbólica ao fazerem a defesa das ideias da elite financeira influenciados pela cobertura jornalística realizada pela grande mídia. Além disso, percebeu-se que os estudantes, na luta de classes, se colocaram a favor daqueles que queriam interromper a ascensão social de sua classe. Dessa forma, percebe-se a importância deste estudo visto que à medida que o estudante compreende a dinâmica de manipulação em que está inserido poderá ser capaz de desenvolver a consciência crítica e superar a ideologia da opressão, da consciência ingênua e acrítica.

Palavras-chave: Manifestações. Produções Literárias. Manipulação. Criminalização da Política.

\footnotetext{
Mestrando em Ciências da Educação pelo Programa de Postgrado da FICS - Facultad Interamericana de Ciencias Sociales - Assunção - Paraguai. Atua como professor da Educação Básica da Rede Estadual de Ensino no município de Candiba - BA, Brasil. E-mail: valdimir.asa@gmail.com
} 


\section{INTRODUÇÃO}

O presente trabalho constitui-se da análise da influência das manifestações de junho de 2013 nas produções literárias dos estudantes de um colégio estadual do sudoeste baiano no tocante a criminalização da política. Para tanto, nos orientamos pelos referenciais de Souza (2016), cujo autor afirma que as manifestações de 2013 marcam um ponto de virada da hegemonia ideológica das altas taxas de aprovação aos presidentes petistas. Além disso, nos apropriamos dos conhecimentos produzidos sobre políticas, corrupção a fim de compreender como estas ideologias influenciou o desfecho político dos últimos anos.

Esta pesquisa apresenta-se relevante uma vez que no ano de 2013 uma grande quantidade das produções literárias dos alunos de um colégio estadual da Bahia trouxe como tema que discutia algum aspecto da sociedade brasileira como política, economia ou organização social, corrupção, sendo que uma parte destes dava destaque à criminalização da política.

Assim, compreender as ideias que influenciaram a forma de pensar dos estudantes permitirá uma prática pedagógica que contribuirá para ajudá-los na construção de um pensamento crítico, que possibilita assumir postura de uma ação libertadora e forneça-Ihes defesa contra a dominação da elite dos proprietários.

\section{AS PRODUÇÕES ARTÍSTICAS DO PROJETO TEMPOS DE ARTES LITERÁRIAS - TAL E AS MANIFESTAÇÕES DE 2013}

Para a realização deste trabalho, fizemos o levantamento bibliográfico dos autores que discutiram as manifestações de 2013 e o tema da criminalização da política. Adotamos a metodologia baseada numa abordagem qualitativa, que, segundo Gil (2008), privilegia a análise de microprocessos, através do estudo das ações sociais individuais e grupais, realizando um exame intensivo dos dados, tanto em amplitude quanto em profundidade.

Recorremos à técnica de análise de conteúdo que, segundo Bardin (1977) trabalha a palavra e tenta compreender os participantes ou o ambiente num momento determinado. Como análise que se apoia nesta perspectiva, trabalhamos 
com as composições estudantis que apresentam um discurso que ocorre dentro de um contexto, buscando desvendar o que está por trás das ideias.

O TAL foi criado pela Secretaria de Educação do Estado da Bahia e começou a ser implantado a partir março de 2009, em toda rede estadual de ensino, e, segundo a Sínteses Dos Projetos Estruturantes - SPE (2015) se tornou o maior projeto de arte literária voltado para a juventude estudantil.

Segundo a SPE (2015) o TAL é composto de três fases: a primeira é interna, ou seja, acontece na escola e o aluno melhor classificado é inscrito para a segunda fase que acontece em nível regional sob a responsabilidade do Núcleo Territorial de Educação (NTE). Este escolhe um para participar do sarau estadual que fica a cargo da Secretaria Estadual de Educação, constituindo assim a terceira etapa.

O estudante tem liberdade para a escolha do tema ou temas a serem tratados na sua produção bem como o gênero textual e gênero literário, ou seja, o aluno não é induzido pelo professor, este deve orientá-lo no sentido de ajudar a melhorar o texto que ele pensou.

O momento da produção dos poemas ocorreu no mês de junho, quando coincidentemente iniciaram os protestos nas capitais e grandes cidades, envolvendo principalmente jovens, e ficaram conhecidos como "Jornadas de junho". Protestos estes que repercutiram na grande mídia, o que levou a ter um forte apoio popular.

$\mathrm{Na}$ perspectiva de Pinto (2017) houve uma tendência de associar as "Jornadas de junho" às manifestações ocorridas na Europa, principalmente na Espanha, devido a sua proximidade temporal, pela forma como foram organizadas e pela grande participação dos jovens. Porém nos momentos dos protestos, a Espanha e o Brasil apresentavam situações opostas do ponto de vista econômico. A taxa de desemprego no Brasil era de $5,4 \%$, sendo que entre os jovens era de $13,7 \%$, enquanto que na Espanha a taxa de desemprego era de $26,03 \%$ e entre os jovens era $53,7 \%$. Nesse período, crise econômica que atingiu a Espanha não tinha chegado ao Brasil.

Recorrendo aos estudos empíricos realizados por Souza (2016), nos quais evidenciam que as manifestações de junho de 2013 foram iniciadas pelo Movimento 
Passe Livre (MPL) que naquele momento lutava contra o aumento de $R \$ 0,20$ (vinte centavos) na passagem de ônibus na cidade de São Paulo.

Souza (2016) mostra que os grandes meios de comunicação mudaram a sua forma de cobertura jornalística no decorrer do protesto. Ele tomou por base o Jornal Nacional (JN) da Rede Globo, por ser a porta-voz da reação conservadora da sociedade. Assim aponta que o JN fez a primeira referência às manifestações no dia 10 de junho de 2013, de forma negativa, enfatizado o tumulto, o prejuízo ao trânsito e o incômodo à população. A cobertura continuou negativa no período de 12 a 16 de junho.

Souza (2016) aponta que a partir do dia 17 de junho a cobertura do JN mudou completamente. O sentido mudou de negativo para positivo. Os protestos passam a ser a "expressão democrática". A bandeira brasileira é incluída como símbolo e os protestos são chamados de pacíficos. A pauta, o aumento das passagens de ônibus, deixa de ser municipal, e é federalizada passando a ser contra a PEC 37, contra a corrupção e contra os gastos da copa do mundo. Nestas manifestações, a política e partidos passam a ser criminalizados.

A partir do dia 19 de junho, segundo Souza (2016) a cobertura do JN passa a ter o objetivo de atingir a figura da presidente da república. Nesta data as tarifas municipais foram reduzidas para os preços anteriores, mas os protestos continuaram, pois os mesmos já tinham sido apropriados por um segmento da classe média, que fez a alteração da sua pauta.

Souza (2016) afirma que as manifestações de 2013 marcam um ponto de virada da hegemonia ideológica das altas taxas de aprovação aos presidentes petistas. Foi o início do cerco ideológico que resultou no impedimento da presidente.

É importante ressaltar que nenhum dos estudantes que fez os poemas participou dos protestos, os seus contatos ocorreram somente pela cobertura realizada pela mídia.

Utilizamos os estudos empíricos de Souza (2009, 2016, 2017) uma vez que este autor traz contribuições sob a forma de pensar do brasileiro, que embasou a interpretação do pensamento estudantil que foi expresso nos textos que abordaram a realidade social e política do país. 
Para Souza (2009) as ideias que serviram de base para a constituição da identidade nacional e da interpretação social e política do Brasil foram lançadas, especialmente, por Gilberto Freyre, Sérgio Buarque de Holanda e por Raimundo Faoro.

Para realizarmos a interpretação das produções do TAL, fez-se necessário entender que um conceito fundamental é de que toda sociedade é constituída de classes sociais. Compreender a sua dinâmica dentro do contexto é essencial para fazer a interpretação da realidade social

$\mathrm{Na}$ perspectiva de Souza (2016) a classe social é uma construção socioafetiva que acontece dentro da família, ou seja, a socialização familiar pelo pertencimento na classe que possibilitará o sucesso na escola e, mais tarde, o sucesso no mercado de trabalho. Souza (2017) esclarece que a luta de classes é a chave para entender tudo que é importante na sociedade. Tal ideia, por um lado, foi demonizada pela direita e, por outro lado, banalizada pela esquerda. Sem a concepção de luta de classes, ficamos com a ideia do senso comum de que na sociedade temos apenas indivíduos competindo em condições de igualdade pelos bens e recursos escassos.

Na visão de Gohn (2016), até 2013, os atores das manifestações de ruas eram os movimentos populares organizados que lutavam pelo acesso à terra e à moradia. Porém a partir de 2013 , os atores das manifestações se alteram, a classe média ocupa os espaços das ruas.

Para Pujol, Rocha e Sampaio (2014) a classe média pode ser compreendida pelas bandeiras que levantou nas manifestações de 2013 a partir de algumas características. A primeira característica foi a de repúdio aos programas governamentais de distribuição de renda que levaram a classe trabalhadora ao acesso de espaços que, historicamente, eram ocupados pelos ricos. Os programas de assistência social foram classificados pela classe média como esmola que induziria a acomodação dos beneficiários.

A segunda característica é a defesa, de forma velada, de que alguns são melhores do que outros, por isso o aumento da capacidade de consumo dos mais 
pobres foi interpretada como um inconveniente, assim a classe média procura resguardar a sua ambição econômica.

Ainda segundo Pujol, Rocha e Sampaio (2014) a terceira característica é a postura dependente e paternalista que a classe média mantém em relação ao aparelho estatal. Essa postura, de tempos em tempos, motiva revolta contra os poderes do Estado que associa tudo que não dar certo como "culpa do governo". Essa atitude foi expressa durante as manifestações.

Para Warren (2014), nas manifestações de 2013, a mídia teve um papel ambíguo no sentido de que, historicamente, desde a ditadura militar, sempre criminalizou os protestos dos movimentos sociais. Em 2013, iniciou condenando as manifestações, mas a partir de um dado momento, passou a exalta-las como as "vozes da rua".

Pujol, Rocha e Sampaio (2014) ressaltam que as mídias sociais tiveram um papel relevante na mobilização em larga escala. Mas a grande mídia já tinha trabalhado, durante dez anos, martelando diariamente a opinião pública com a condenação seletiva da corrupção, contra os gastos públicos e os impostos que aparecem nos slogans das manifestações.

Ainda segundo Pujol, Rocha e Sampaio (2014) pela falta de lideranças de movimentos sociais ou de partidos políticos, os protestos tiveram uma agenda pulverizada e permitiram que os meios de comunicação de massa apoderassem das manifestações, oferecessem o conteúdo político e realizassem a interpretação à sua maneira.

Essas interpretações foram usadas para produzir aglomerações que conduzissem a consequência de exigir mudanças no poder vigente. Por outro lado, os manifestantes, desejavam fazer a figuração do espetáculo, por isso expressavam o orgulho de sua participação.

Os resultados das manifestações de 2013 na visão de Souza (2016) foram o "ovo da serpente" que possibilitou a construção da "base popular" do golpe de 2016. No intervalo desses três anos, a grande mídia fez o ataque sem tréguas ao governo federal, até a vitória do impeachment. 


\title{
A CRIMINALIZAÇÃO DA POLÍTICA NAS PRODUÇÕES LITERÁRIAS DOS ESTUDANTES EM 2013
}

Em algumas produções literárias, os estudantes fizeram direta ou indiretamente referência a criminalização da política, inclusive ao tema da corrupção serviu a esse propósito, quando foi percebida como uma prática exclusiva de quem cumpre uma função pública no Estado. Evidenciaram também um forte apelo à mudança, no sentido de fazer a alteração de governo.

Apresentamos a seguir trechos das composições do TAL 2013, que fazem a criminalização da política:

\author{
Você culpa o político por tudo \\ Isso é correto \\ São manifestantes como você \\ Que estão certos \\ Assim como você!
}

O estudante Citrino, com o poema "As verdades do país", aponta que a causa dos problemas de corrupção e suas consequências têm um culpado que é aquele que exerce o poder político. No entendimento do estudante, o político é culpado por tudo que acontece de ruim na sociedade ou o que não presta tem a sua participação. Dessa maneira, faz a demonização do político.

A estudante Esmeralda, com a composição "Brasil, um país de conquista", apresenta que os agentes políticos, a partir das manifestações, tiveram mudança de postura. No entendimento da estudante, antes destes protestos, os que exerciam os mandatos políticos estavam insensíveis e comportavam como cegos, porque não enxergavam os problemas da população e, como surdos porque não ouviam o clamor de suas necessidades.

Políticos que antes se faziam cegos e surdos

Hoje são obrigados a ceder a essa manifestação 
Dá para interpretar que os detentores de mandatos podem ser pressionados por manifestações e, por medo, de talvez perderem os seus mandatos, podem mudar de posição. Nesse sentido o político é visto como alguém que sempre age para prejudicar a população. Então parece crítico sempre ser contra a política desenvolvida seja lá por quem for.

No poema da estudante ainda podemos interpretar que todo político se não estiver pressionado pelos cidadãos, irá fazer o mal à sociedade. Além disso, podemos entender que a estudante descarta o apoio a qualquer ato para desenvolver alguma política social, ou que toda política tem sua base de apoio.

O estudante Rubi, com o poema "O povo que paga", numa referência ao agente político, usa a expressão "o povo que acha que Brasília tem esplendor" e conclui que lá "rouba, sem medo e pudor". Como se percebe, ele acredita que todos os políticos são ladrões, ao fazer esta generalização.

\author{
O povo que acha \\ Que Brasília tem esplendor. \\ Que vive enganando \\ Do outro que rouba, sem medo nem pudor
}

O estudante Rutilo traz no seu poema "Acorda Brasil!!" a expressão "O movimento é pelo País" como se fosse para dizer: o movimento não é por nenhum partido ou por alguma luta de interesse de uma categoria profissional. No entendimento dele, as manifestações estão acima de qualquer luta de classe ou que os partidos lutam somente por interesses próprios.

\title{
O movimento é pelo País
}

Percebe-se que estas composições receberam influências das manifestações de junho de 2013 uma vez que estes protestos referiram de forma agressiva à política e aos que exercem mandatos eletivos.

Neste sentido, Barbosa (2016) relata que durante as manifestações de 2013 havia pessoas que eram apartidárias, ou seja , não integravam a nenhum partido, outras eram antipartidárias e faziam a demonização dos partidos, hostilizando-os 
nos protestos. Warren (2014) observa que os manifestantes expressavam intolerância e antagonismos em relação às siglas partidárias presentes no movimento.

Pinto (2017) comenta que em pesquisa realizada pelo Instituto Brasileiro de Opinião e Estatística (IBOPE), no dia 20 de junho de 2013, com relação à política, 96\% não tinha nenhuma filiação e $86 \%$ não participava de nenhuma entidade de classe como sindicatos ou entidades estudantis. Assim, Pinto (2017) conclui que a maioria dos jovens que estava nas ruas naquele protesto não tinha nenhuma experiência partidária ou associativa.

Durante as manifestações apareceram muitos cartazes que eram confeccionados à mão pelos próprios participantes, como enumera Pinto (2017), com dizeres: o povo unido não precisa de partido, ou para a roubalheira ou paramos o Brasil, meu partido é meu país.

[...] Criticavam a política e os políticos, pediam mais recursos para a saúde e a educação, mas vinham de setores menos populares do que aqueles aos quais pertenciam os costumeiros usuários desses serviços públicos"(PINTO, 2017, p. 136).

Souza (2016) assegura que a cobertura da televisão explicava que as manifestações contra o governo eram espontâneas e apartidárias, por isso os integrantes de partidos foram hostilizados. Assim, criou um sentimento de que se tivesse ligação a algum partido teria uma visão restrita e lutava só por interesses particulares, enquanto quem não estivesse vínculo partidário lutava pelo interesse público.

Por este ângulo, Pinto (2017) identifica que até a redemocratização do país, a partir de 1980, os manifestantes que iam às ruas eram identificados com posições políticas de esquerda e de centro-esquerda, a partir de 2013 se identificam com posições de direita e de centro.

Argumenta ainda que, a partir desta data, as lutas não são mais por direitos, por serviço público de qualidade, melhores salários. As manifestações são conduzidas por 
referir à presidenta da República e lutar por seu impeachment (PINTO, 2017, p. 152).

Neste contexto, Souza (2016) assegura que os atores das Jornadas de junho foram a fração moralista e conservadora da classe média, um velho conhecido da história brasileira, que sempre desprezou e odiou pobre, mas a reconstrução desse segmento foi realizada para parecer um novo ente. Nessas manifestações, a camisa da seleção brasileira de futebol e o Hino Nacional se tornaram símbolo. "[...]É a camisa que passa a mensagem mais importante: 'não somos de nenhum time, não somos de nenhum partido. Nosso time é a seleção, e torcemos pelo Brasil'” (SOUZA, 2016, p. 101).

Diante dessas manifestações surgem os questionamentos, qual o sentido de criminalizar a política? Quem ganha e quem perde com essa criminalização? Para isso, realizamos a análise dessa compreensão nas produções dos estudantes e o que significa para as classes populares a cimentação da criminalização da política.

Segundo Souza (2017) as noções de personalismo e de patrimonialismo, já abordado na seção anterior, criou a ideia de tratar com desconfiança todos aqueles que assumem o poder político. Mesmo não tendo comprovação de um desvio de conduta de um agente político, a imprensa pode acusá-lo, pois este ato já está legitimado pela forma de pensar do brasileiro que não acredita que nenhum político não faça desvio de recursos públicos.

Assim, acusar uma pessoa que tem mandato político de corrupção é um ato banal e o acusador já recebe a credibilidade, pois há crença no senso comum e até na ciência para justificar a acusação. Nesta situação fica a cargo do acusado provar que é inocente, se for algo que lhe interessa.

A corrupção apresentada pela mídia, que só condena o agente público do estado, é uma forma de criminalizar a política. É comum ouvir expressões como: "todo político é corrupto" ou "quem é honesto não entra em política" e ainda "toda pessoa honesta que entra na política se corrompe". Essa forma de tratar a política partidária faz que uma grande parte das camadas populares se afaste desta atividade e, por isso, tem pouco poder na formulação das políticas públicas.

Em se tratando de corrupção na política faz-se necessário atentar para o que nos escreve Souza: 
Repare o leitor que jamais se reflete acerca de um sistema político construído para ser corrupto, ou seja, construído para ser comprado pela elite do atraso para manter seus privilégios econômicos (SOUZA, 2017, 123).

Procurando esclarecer a compreensão de Souza (2017), que nos indica que o sistema político foi montado para ser corrupto e garantir a elite do dinheiro no poder pelo sistema de financiamento de campanha, vemos que a grande parte dos agentes políticos eleitos tiveram suas campanhas financiadas (compradas) e, portanto, defendem os interesses de seus corruptores, mas "[...] o ataque midiático é feito para parecer que a corrupção é obra de pessoas privadas ou partidos específicos". (SOUZA, 2017, 123)

Souza (2017) sustenta que os motivos para criminalizar a política são em primeiro lugar uma forma de tirar das camadas populares a possiblidade de participar da intervenção dos destinos do Estado. Ele também nos chama atenção que sempre partiu do Estado, as poucas vezes que se teve alguma preocupação com a ascensão das camadas populares.

Numa sociedade como a nossa, que tem uma enorme desigualdade social, deixar a maior parte da população de fora da decisão da divisão do bolo, é o que gera a maior concentração de renda na mão de poucos ricos e a perpetuação da pobreza extrema.

Souza (2016) ressalta que os ataques da mídia a Lula e ao PT não foram ataques a pessoas e a partidos, "[...]foram ataques a uma política bem-sucedida de inclusão das classes populares que Lula e o PT representaram" (SOUZA, 2016, p. 85).

Outro motivo que Souza (2017) menciona para criminalizar a política é para que a economia não tenha a sua mediação e fique a serviço da elite do atraso e não tenha o controle do Estado, deixando-a para a influência do mercado, que faz a rapinagem dos recursos públicos.

Continua discorrendo Souza (2017) que a interpretação de Sérgio Buarque de localizar uma elite maldita no Estado é uma forma de tornar invisível o mercado dominado por atravessadores financeiros. Dessa forma, constrói-se o Estado 
corrupto e o mercado o seu oposto, assim o Estado é sempre suspeito, principalmente se é dirigido por alguém que não está disposto a fazer o jogo do mercado de capturar o Estado para si.

Souza (2016) aponta que nas manifestações de junho de 2013, os partidos políticos foram criminalizados, mas como só os partidos de esquerda têm capilaridade e militância, somente eles foram afetados por essa visão. Dessa forma, a esquerda foi criminalizada e consequentemente perdeu expressão política para fazer a defesa do princípio da igualdade social, o que deixou vulneráveis as camadas mais pobres.

Dessa forma, um dos motivos para criminalizar a política é tirar dos mais pobres as possiblidades da ascensão social. Como nos indica Souza (2017) que foi por meio da política que os governos petistas iniciaram a elevação da condição de vida da ralé e se essas políticas fossem levadas a diante, em poucas gerações, redimiria essa classe.

Por isso, como argumenta Souza (2017), a elite e a classe média, nas manifestações de 2013, reagiram pedindo mudanças, como forma de retirar o governo e consequentemente alterar as políticas sociais de atendimento às classes populares. Porém, as camadas populares ficaram quietas e "[...] passivas e algumas vezes, inclusive, açodando e participando do movimento" (Souza, 2017, p. 89).

Nas composições do TAL, os estudantes assumem esse papel ao defenderem, nos seus poemas, esse apelo de mudança que vinham das manifestações, como apresenta o poema da estudante Safira:

\footnotetext{
Temos que pensar em mudanças

Lutando por igualdade

Branco, preto e mulato

Todos nós vamos em busca de liberdade.
}

Com o poema "Dificuldades" está Safira convencida da necessidade de fazer mudanças. A cobertura jornalística que foi realizada conseguiu persuadi-la de que as manifestações estavam lutando por igualdade entre os brasileiros. Ao fazer a citação "branco, preto e mulato", apesar de não está incluído o índio, dá para interpretar que todo brasileiro está incluído nesta luta de superação de desigualdade. 
Percebe-se que o tipo de informação recebida pela estudante foi distorcida para fazê-la acreditar que, ao realizar a defesa das mudanças proferidas nos protestos, estava lutando para que todos buscassem a sua liberdade e sua autonomia.

O poema "As verdades do país" de autoria do estudante Citrino demonstra o desejo de morar em outro país, mas a suas condições financeiras não the oferecem possibilidade de concretização deste sonho. Avalia ainda que não encontra ninguém para ajuda-lo, naquele momento e nem em situações anteriores, que teve grandes necessidades, por isso conclui que tem de concretizar a mudança.

\author{
Eu moro nesse país \\ Mas as condições não dão pra \\ Eu morar em qualquer lugar \\ Não vejo ninguém para me ajudar \\ Já precisei de tantas coisas \\ E não puderam me ajudar \\ A gente precisa de mudança
}

O pedido de mudança do estudante é como um "passo no escuro", porém, ele tem a expectativa de que a transformação, na qual acredita que virá, criará as condições para a realização do seu desejo ou que qualquer alteração que possa vier, será melhor do que o presente que ele vive.

A estudante Esmeralda com a composição "Brasil, um país de conquista" apresenta, ao observar os protestos, que o Brasil tem um desejo grande de mudança e ressalta algumas características de elevação do país, tais como: forte, inovador e que não perde a esperança. Por seus traços de grandezas, o país tem condições de fazer as alterações que deseja.

\footnotetext{
És forte!

Nunca perde a esperança

De um país inovador

Com sede de mudança
}

Como identifica Souza (2016), a partir das manifestações de 2013, mediante a parceria entre grande mídia e as instituições do aparelho jurídico-policial passaram a deslegitimar o governo. "[...]Palavras de ordem como 'muda Brasil', como forma 
cifrada de invocar a verdadeira bandeira 'muda (de governo) Brasil' passaram a dominar o imaginário das manifestações" (Souza, 2016, p. 94)

Acreditamos que as produções dos poemas citados acima, foram fortemente marcadas pelo tipo de cobertura realizado pela mídia no momento das manifestações de 2013.

\section{CONCLUSÃO}

Diante do exposto, procuramos evidenciar que a criminalização da política e o pedido de mudança, mais no sentido de alteração do governo federal, foram influenciados pelas manifestações de junho de 2013, que tiveram uma enorme cobertura jornalística realizada pela grande mídia. Tal postura serviu para criminalizar os partidos de esquerda e interromper a progressão das políticas de inclusão social que vinham superando as desigualdades abissais no Brasil.

Os estudantes ainda não tinham a compreensão de que toda política tem que ter sua base social para dar sustentação ao seu desenvolvimento. A consequência mais danosa de seguir uma narrativa feita pela grande mídia, a partir das manifestações de 2013, foi por freio no processo de ascensão social das camadas populares.

Entendemos que o pensamento defendido nas manifestações de 2013, que reverberou nas produções textuais dos estudantes, fomentou as disputas políticas a partir de então, sendo propulsora das ideias e da base social responsável pelo golpe no mandado popular da presidenta Dilma. Ademais, a partir dessas manifestações é que começam a ganhar força as políticas de redução de direitos das camadas populares.

Olhando esta situação sob a ótica de Bourdieu e de Souza, podemos afirmar que os estudantes foram vítimas da violência simbólica que a classe dominante impõe sobre a classe trabalhadora e da ralé, quando estes estudantes fizeram a defesa das ideias da classe dominante que estavam sendo levadas às ruas pela classe média e amplamente divulgada pela grande mídia. 
Segundo Souza (2017) que o principal instrumento de disseminação da violência simbólica e portanto de dominação no Brasil "é uma imprensa desregulada e venal, que vende uma informação e uma interpretação da vida social enviesada pelos interesses do pacto antipopular" (SOUZA, 2017, p. 119). Tal situação acontece porque a imprensa está sob o controle da elite e porque ela é dependente dos seus anunciantes.

A partir deste estudo chegamos ao entendimento que se faz necessário o uso de ferramentas pedagógicas que permita ao estudante o seu autoconhecimento, enquanto classe social. Essa auto-identificação, enquanto classe social the possibilitará saber que as classes estão em luta constante e the permite pensar em se colocar do lado de sua classe, não oferecendo as suas forças para opressão, mas para a sua libertação.

Esperamos que os estudos e discussões apresentados neste trabalho científico contribuam para fortalecer as práticas educativas libertadoras na formação cidadã e no combate às ideologias que visam à opressão, pois a educação libertadora é capaz de desenvolver a consciência crítica e perceber os fios que tecem a realidade social e superar a ideologia da opressão, da consciência ingênua, acrítica (MENEZES, 2014).

\section{REFERÊNCIAS}

BARDIN, Lawrence. Análise de Conteúdo. Lisboa: Edições 70, 1977.

BOURDIEU, Pierre. O Poder Simbólico. $2^{\underline{a}}$ Ed. Rio de Janeiro: Editora Bertrand Brasil LTDA, 1989.

GIL, Antônio Carlos. Métodos e Técnicas de Pesquisa Social. 6 Edição. São Paulo: Atlas, 2008.

GOHN, Maria da Glória Marcondes. Manifestações de protesto nas ruas no Brasil a partir de Junho de 2013: novíssimos sujeitos em cena. Rev. Diálogo Educ. Curitiba, v. 16, n. 47 , p. 125-146, jan./abr. 2016.

PINTO, Céli Regina Jardim. A Trajetória Discursiva das Manifestações de Rua no Brasil. Lua Nova: Revista de Cultura e Política. São Paulo, fev-2017.

WARREN, Ilse Scherer. Manifestações de Rua no Brasil 2013: encontros e desencontros na Política. Caderno CRH. Salvador, maio/ago - 2014, v. 27, № 71. 
PUJOL, Antoni Francesc Tulla i; ROCHA, Fernando Goulart; SAMPAIO, Fernando dos Santos. Manifestações populares no Brasil atual: sociedade civil em rede e reivindicações sobre o poder político. XIII Coloquio Internacional de Geocrítica. Barcelona, 5-10 de mayo de 2014.

SOUZA, Jessé. A Elite do Atraso: da Escravidão à Lava Jato. 1ㄹ. Ed. Rio de janeiro: Leya, 2017.

SOUZA, Jessé. A radiografia do Golpe: entenda como e porque você foi enganado. 1a. Ed. Rio de janeiro: Leya, 2016.

SOUZA, Jessé. A Ralé Brasileira: Quem São e Como Vive. 1a․ Ed. Belo Horizonte: Editora UFMG, 2009. 